\title{
Artelogie
}

Recherche sur les arts, le patrimoine et la littérature de l'Amérique latine

5 | 2013

Femmes créatrices en Amérique latine : le défi de synthétiser sans singulariser

\section{Editorial: Mujeres creadoras en América Latina: el desafío de sintetizar sin singularizar}

Ana Paula Cavalcanti Simioni, Deborah Dorotinsky y Maira de Luca

\section{OpenEdition}

Journals

Edición electrónica

URL: https://journals.openedition.org/artelogie/5078

DOI: 10.4000/artelogie.5078

ISSN: $2115-6395$

Editor

Association ESCAL

Referencia electrónica

Ana Paula Cavalcanti Simioni, Deborah Dorotinsky y Maira de Luca, «Editorial: Mujeres creadoras en América Latina: el desafío de sintetizar sin singularizar», Artelogie [En línea], 5 | 2013, Publicado el 16 octubre 2013, consultado el 20 diciembre 2021. URL: http://journals.openedition.org/artelogie/5078 DOI: https://doi.org/10.4000/artelogie.5078

Este documento fue generado automáticamente el 20 diciembre 2021.

Association ESCAL 


\title{
Editorial: Mujeres creadoras en América Latina: el desafío de sintetizar sin singularizar
}

\author{
Ana Paula Cavalcanti Simioni, Deborah Dorotinsky y Maira de Luca
}

1 Entre 1974 y 1979, dentro del movimiento feminista de los años setenta la artista norteamericana Judy Chicago concibió su emblemática obra, Dinner Party (1979), como un banquete simbólico que reunía 1038 mujeres, de diferentes períodos históricos, estando 39 de ellas evocadas en la mesa, en tanto las demás eran nombradas en las losetas cerámicas dispuestas en la gran instalación, de tal suerte que se celebraba-y a la vez se promovía-una tradición femenina hasta entonces no reconocida por la historiografía dominante. En esa gran comunidad, se hicieron evidentes algunos límites etnocéntricos del feminismo anglosajón , como notó entonces Estelle Chacon, ninguna de las heroínas del "nuevo mundo" figuraba entre las invitadas a compartir la mesa, por el contrario, las "hispanas" aparecían, como las negras, nombradas apenas en algunas de las baldosas, aquellas dispuestas en el suelo, señalizando el lugar simbólico que ocupaban en esa narrativa propuesta por el feminismo que despuntaba en los Estados Unidos e Inglaterra ${ }^{1}$.

2 Las reacciones a la obra, convertida en uno de los íconos del feminismo de "igualdad", no se hicieron esperar. Ya desde 1977 Griselda Pollock había realizado en su texto "What's wrong with the images of Women" una denuncia de aquello que denominó "iconografía vaginal", que tendía a reducir las múltiples identidades femeninas a un supuesto significante estable, derivado de sus cuerpos biológicos. Contra una imagen unívoca, Pollock, quien seguramente es hoy el nombre más influyente en la historiografía feminista del arte, proponía una deconstrucción de las imágenes femeninas, una crítica a los discursos estabilizadores, en fin, a todo tipo de reducciones, incluso a aquellas operadas por el feminismo. A partir de la década de 1980, groso modo, se puede decir que el feminismo de "igualdad" cedió paso al de la diferencia. Para el campo de la crítica literaria postcolonial, es importante notar la contribución de Gayatri Chakavorty Spivak en "Imperialism and Sexual Difference" (1986), al apuntar la 
necesidad de pasar de un feminismo meramente "oposicional" a un feminismo "crítico", capaz de examinar continuamente la forma como el propio feminismo se imbrica en las instituciones e ideologías. En ese sentido, autoras como Chéla Sandoval (1995), jugaron un papel importante en la problematización el feminismo anglosajón de los años 1960/70, que presuponía un sujeto feminista único, estable, hegemónico, lo cual no se traducía en una atención a las expectativas, deseos o realidades vivenciada por las "otras del feminismo". Así, las cuestiones "femeninas" pasaban a ser atravesadas por tónicas de clase social y etnicidad.

3 Se puede decir que en el campo artístico el debate fomentó análisis que pasaron a atender la relevancia de las imágenes de las mujeres propagadas por las obras de arte, los medios, la prensa y el cine, como espacios fundamentales de promoción y cristalización de discursos sociales normativos; éstos pasaron a ser considerados como “tecnologías de género" (De Lauretis, 1987). Desde entonces, más que promover imágenes positivas de la femineidad, la historiografía feminista del arte, pasó a detenerse en la crítica de tales representaciones (Arruda, 2013).

4 Sin embargo, cuando pensamos en el campo de los estudios de género y arte en América Latina, nos encontramos con una situación compleja, pues esa historia del pensamiento feminista no transcurre como la que narramos arriba; muchas veces los textos del feminismo de "igualdad" y de la "diferencia" llegan a manos de los lectores en un mismo intervalo temporal. Además de eso, las investigaciones realizadas se nutren de los paradigmas desarrollados por las teorías anglosajonas, las cuales tienen como marco fundacional el célebre artículo de Linda Nochlin (1971). En "Why have there been no great women artists?" la autora argumentó que el poco reconocimiento de las mujeres en la historia del arte resultaba de factores sociales e institucionales, en especial del acceso desigual a las condiciones de formación artística, estableciendo así los parámetros sobre los que se asentaría una historiografía feminista del arte. Sin embargo, es preciso reconocer que las múltiples realidades contenidas en el término "América Latina" son por demás diversas de aquellas que propiciaron la emergencia de tales teorías feministas de suerte que necesariamente ellas deben ser revisitadas, adaptadas o incluso reelaboradas cuando se las contrasta (o coteja) con los diferentes contextos que se les presentan ${ }^{2}$. Además es preciso recordar que la recepción de los postulados de Nochlin, por ejemplo, no ocurrió de manera simultánea o ecuánime en los países de América Latina. Si en México, ya desde inicios de la década de 1970 tales textos circulaban e impactaban desde las discusiones universitarias, llegando a las instituciones artísticas, como bien demuestra el artículo de Andrea Giunta aquí publicado, en otros casos, como el del propio Brasil cuya producción artística femenina y feminista es considerable, incluso hoy día ese texto célebre no ha sido traducido al portugués, evidenciando una circulación restringida. Entre estos extremos, se puede citar el caso de Argentina, cuya capital, Buenos Aires, fue el escenario de varias experimentaciones feministas durante los años setenta, como bien analiza María Laura Rosa en "El despertar de la conciencia. Impacto de las teorías feministas sobre las artistas de Buenos Aires durante las décadas del ' 70 y ' 80 ”, producciones contestatarias realizadas desde los márgenes del sistema artístico. Como afirma Luana Saturnino Tvardovskas, en "Tramas feministas na arte contemporânea brasileira e argentina", el hecho de que las producciones feministas en Brasil y Argentina se organizaran de modo diferente al de los países anglosajones, de manera menos institucionalizada, menos identitaria, sin grandes exposiciones colectivas o una revisión más contundente del canon, no resta fuerza a las poéticas feministas contenidas en muchas de las obras ahí 
producidas. Tales consideraciones son relevantes para que se entienda la dificultad (¿o imposibilidad?) de construir un andamiaje teórico y metodológico único para comprender producciones y situaciones históricas tan diversas entre sí.

5 De este modo, el presente número de la revista Artelogie pretende contribuir al debate sobre arte y género al abarcar un panorama amplio y variado de investigaciones sobre las mujeres artistas en América Latina, desde el siglo XIX hasta las expresiones contemporáneas. No se trata de buscar una teoría monolítica, o un mapeo completo y exhaustivo sobre la producción de las mujeres artistas en toda América Latina. Ante todo, presentamos al lector una selección de textos que poseen densidad analítica y verticalidad, pero que cubren experiencias, producciones y poéticas realizadas en diferentes países en un período temporal relativamente largo. Procuramos priorizar aquellas modalidades artísticas que cuentan con menos publicaciones (como las artes plásticas, la música y el diseño), lo cual implicó una opción por no abordar las prácticas literarias, que cuentan ya con una larga tradición.

6 En un primer bloque, están reunidos los ensayos que analizan de qué modo las dimensiones de género atraviesan los procesos de constitución de los discursos identitarios que hacen eclosión a lo largo el siglo XIX en diversos países de América Latina, en el seno de las luchas por la autonomía política. Tales discursos se materializan en-y por medio de-las formas artísticas. Al lado de las novelas fundacionales (Doris Sommer, 2010), las pinturas constituían verdaderos discursos visuales de carácter pedagógico, en las cuales por medio de articulaciones complejas (y tensas), ciertas dicotomías vistas entonces como aparentemente irreconciliables como civilización/barbarie, dominadores (blancos)/dominados (indígenas o negros), activos/ pasivos, hombres/mujeres, podían trascenderse, apaciguarse o domesticarse. En ese proceso civilizatorio conflictivo, que envuelve al dilema del mestizaje, el cuerpo femenino ocupa un espacio político, visual y simbólico central, bien en Chile, como demuestra el artículo de Josefina de la Maza sobre las pinturas de Monvoisin, particularmente Elisa Bravo Jaramillo de Bañados, mujer del cacique, o en la joven república brasileña, como bien analizan Tatiana Lotierzo y Lilia Katri M. Schwarcz, deteniéndose en la célebre tela Redenção de Cã, pintada por Modesto Broccos.

Otro conjunto de artículos aborda por medio de distintas prácticas artísticas como la música, el grabado, la pintura o la escultura, el ingreso de las mujeres artistas en aquello que podríamos llamar "modernidades periféricas" (Sarlo, 1999). La inserción femenina en los medios artísticos se muestra a lo largo del siglo XIX en diversos países latinoamericanos, en especial, en aquellos que pasaron por un proceso de institucionalización de las rutinas artísticas en base a los modelos de ultramar, que culminaron en la fundación de las Academia de arte, como las de México, Brasil, Argentina y Chile. De modo general, se seguía el modelo de la Academia Francesa postrevolucionaria que no preveía incluir a las mujeres como discípulas, pero las aceptaba como expositoras en los Salones (Simioni 2008). Eso significaba que las mujeres no poseían un acceso pleno a la formación artística, tal como sus colegas hombres, no obstante, ciertas habilidades eran no sólo toleradas, sino fomentadas en la medida en que eran constitutivas de los ideales de feminidad burguesa que se diseminaban en esas naciones.

8 Conforme demuestra Georgina Gluzman en "El trabajo recompensado: mujeres, artes y movimientos femeninos en la Buenos Aires de entre-siglos", en Argentina se configuraba una situación ambigua, permeada de tensiones que provenían, por un lado, 
de las expectativas sociales normativas sobre la feminidad anhelada, y por otro, de las condiciones concretas de profesionalización que disfrutaban. En "Del caballete al telar. La Academia Nacional de Bellas Artes, las escuelas profesionales y los debates en torno de la formación artística femenina en la Argentina de la primera mitad del siglo XX", Julia Ariza expresa ese panorama al enfocarse en las condiciones de formación artística a la cual tenían acceso las mujeres en la Argentina, en pleno proceso de modernización. Gloria Cortez aborda la misma problemática a partir del caso de las artistas chilenas en "Estéticas da resistencia: las artistas chilenas y la vanguardia femenina (1900-1936)", donde discute los obstáculos enfrentados por las artistas para recibir una formación artística, así como las modalidades estéticas de "transgresión" que lograron efectuar contra el discurso patriarcal vigente. En "Género y cultura visual. Adrienne MacaireBacle en La historia del arte argentino", Lia Munilla, Sandra Szir y Georgina Gluzmann recuperan la actuación pionera de Macaire-Bacle como grabadora, a inicios del siglo XIX en Buenos Aires. A través de una investigación original en fuentes de época, las autoras discuten la producción desatendida de esa artista, realizada en un formato considerado "menor" y esencialmente "masculino". Otra autora que también entreteje en el análisis la discusión del género y las modalidades artísticas es Dalila Vasconcellos en "Du salon à la scène: l'ascension des femmes et du piano au brésil du vingtième siècle", donde interpreta las transformaciones en el campo musical brasileño en la Belle époque (c.1889-1930), cuando emergen tres pianistas notables (Antonieta Rudge, Magda Tagliaferro e Guiomar Novaes). La autora muestra como paulatinamente la condición de concertista de piano se convirtió en una prerrogativa femenina, y señala cómo las trayectorias y producción de estas músicas fueron capaces de conformar una superación de las asimetrías tradicionales de género, de tal suerte que emergió una nueva posición para ellas en el campo musical brasileño, un lugar socialmente legítimo y reconocido.

9 Retomamos aquí el término de "modernidades periféricas" pues en las regiones hispano y luso parlantes, los artistas de las vanguardias modernistas adoptaron y adaptaron algunas de las formas derivadas de los repertorios denominados "étnicos" y/ o "populares", desarrollando así un modernismo híbrido, o "antropofágico", como también se le llamón. En ese sentido, algunos artículos son muy reveladores de las inserciones femeninas en los campos dominados, hasta entonces, por los hombres: la Arquitectura y el Diseño Industrial entre los años de 1930 y 1950 en México y Brasil. En “Lina Bo Bardi et l' architecture brésilienne de l' aprés guerre", Zeuler R. M. de Lima muestra el desarrollo de la carrera arquitectónica y obra de Lina Bo Bardi, arquitecta italiana radicada en Sao Paulo hacia finales de la segunda gran guerra y quien realizó obras importantes para el modernismo brasileño, como el emblemático edificio del MASP (Museo de Arte de Sao Paulo), que aunque poco reconocida internacionalmente, su notoriedad se ha acrecentado en los últimos años ${ }^{4}$. Por su parte, Ana Elena Mallet recupera la trayectoria de Clara Porset, diseñadora industrial de origen cubano, radicada en México, y muestra como sus vínculos estratégicos con los arquitectos reconocidos le permitieron destacar, por medio de proyectos de diseño de interiores y mobiliario, su visión acerca de la recuperación y adaptación de las formas derivadas del mobiliario popular mexicano. También hay que notar que Lina Bo Bardi tuvo una contribución teórica fundamental para la valoración del artesanado brasileño ${ }^{5}$. El problema de la articulación entre los ímpetus internacionalistas del modernismo y las tendencias locales/nacionales/populares experimentadas y movilizadas por las artistas de América Latina es también abordado por Michele Greet, quien propone un análisis 
comparativo de las exposiciones realizadas por 4 artistas latino-americanas en París durante los años 1920: las brasileñas Tarsila do Amaral y Anita Malfatti, la mexicana Lola Velásquez Cueto y la cubana Amélia Pelaez. La autora demuestra como cada una de ellas estableció distintas estrategias para hacerse notar en el medio parisino, lo cual involucró decisiones sobre los asuntos a ser representados, así como sobre la materialidad en sus obras, poniendo en evidencia cuanto tales decisiones involucraban negociaciones muy complejas sobre las implicaciones de género para cada estilo adoptado. Como nos permiten comprender los artículos aquí publicados, la dimensión de género discrimina no sólo autores y modalidades, sino también involucra la propia materialidad de las prácticas artísticas, y los niveles de legitimidad con los que éstas son clasificadas en los campos artísticos en los que se inscriben.

10 Finalmente, hay un número significativo de artículos que aproximan los trabajos de las mujeres artistas en el arte contemporáneo, revelando una variedad de temáticas que les preocupan; el cuerpo, la sexualidad, la historia de las mujeres y las prácticas coloniales,

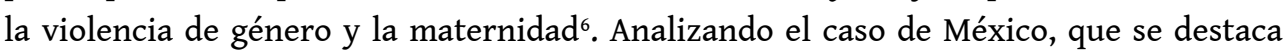
como un centro importante de producción y reflexión sobre las prácticas feministas en América Latina durante los años de 1970, tenemos los textos "Cosas de mujeres? Feminst networks of collaboration in 1970's Mexico", de Gabriela Aceves, y "Feminist Disruption in Mexican Art, 1975-1987”, de Andrea Giunta. El artículo de Giunta propone una lectura de las intervenciones realizadas por algunas artistas-Pola Weiss, Mónica Mayer, Magali Lara y la periodista y activista feminista Ana Victoria Jiménez-quienes hicieron posible un escenario feminista en los medios artísticos mexicanos: introdujeron corporalidades transgresoras e insubordinadas, que frecuentemente fueron invisibilizadas por la propia historiografía del arte feminista del país. El texto contribuye así, a una lectura que libera los potenciales de tales obras poco convencionales, interviniendo en un corpus de imágenes inmovilizadas por las clasificaciones rígidas de los discursos de la historia del arte.

El potencial político y estéticamente transgresor de las mujeres artistas también es abordado por una gama de artículos que revisitan producciones realizadas durante los contextos autoritarios que afectaron a diversos países durante las décadas de 1960 a 1980. Las obras como espacios de resistencia política y como oposición al discurso sobre la domesticidad femenina "natural" son interpretados por Giulia Lamoni em "(Domestic) Spaces of Resistance: Three Artworks by Anna Maria Maiolino, Letícia Parente and Anna Bella Geiger", centrado en el caso brasileño y están también presentes en el artículo de Gina McDaniel Tarver sobre la escultora colombiana Feliza Bursztyn. La misma problemática reaparece en el artículo de María Laura Rosa, que se demora en las obras de María Luisa Bemberg y Monique Altschul, exhibiendo el grado de conciencia feminista política y artística presente en ciertos circuitos artísticos porteños en plena dictadura. El artículo de Luana Saturnino aborda la producción de dos artistas, una argentina y una brasileña, activas durante el período de transición a la democracia en ambos países (años 1980 y 1990), quienes, sin embargo, son herederas de una poética feminista que hace eclosión y se desarrolla en los decenios anteriores marcados por un feroz autoritarismo. Es interesante notar que tales poéticas feministas consisten en "maniobras radicales"7 que buscan cuestionar los discursos ideológicos vigentes por medio de la propia materialidad de las obras. Recuperando modalidades como la costura, el bordado, la decoración, las obras textiles, las acuarelas, que se tenían tradicionalmente como artesanías o bien "obras domésticas", y por tanto estéticamente inferiores, estas artistas operan dislocando los sentidos tradicionales de 
esos medios, o dotándolos de nuevos sentidos; con ello revelan el modo en que las asimetrías y desigualdades sociales se inscriben en los propios mundos del arte. Subvertir, dislocar y deconstruir las imágenes de feminidad pasa, de ese modo, a transformar las propias modalidades, prácticas y jerarquías artísticas vigentes.

Ese notable conjunto de artículos traza un panorama bastante complejo y contundente sobre la contribución de las mujeres artistas a la crítica política. Como afirma Nelly Richard, la condición de doblemente dominadas, permitió a las artistas transitar de la "marginalidad como exterioridad del poder al margen como cuestionamiento del simbolismo del poder" (Richard, 2011: p. 40). Sin embargo, es preciso señalar, que aunque las obras sean contundentes, eso no significa que las artistas se identifiquen a sí mismas como "feministas", muchas de ellas se rehusaban, e incluso hoy día se rehúsan, a ser catalogadas como feministas. Con ello es preciso destacar la diferencia reconocida desde las prácticas artísticas y políticas entre un deseo de militancia "general" y una militancia feminista tout court. Muchas de las artistas aquí analizadas poseen obras que señalan una poética feminista, sin que sus autoras se vean atraídas a ningún tipo de militancia externa al propio campo artístico.

13 Se percibe en los textos que se aproximan a la producción contemporánea una transformación en los medios usados por las artistas: dominan la fotografía, el video, la instalación y el perfomance, o incluso los medios mixtos (mixed media). En el caso de la artista puertorriqueña Elsa María Melendez, abordado por Raquel Torres-Arzola, la manipulación de técnicas mixtas como la serigrafía, o el grabado en bordado y el montaje en cajas, sirven como elementos para proponer una sintaxis propia sobre los escenarios sociales de circulación del cuerpo femenino. También podemos constatar el uso de la apropiación y resignificación del imaginario tradicional, de forma notable, como en el cao de la artista brasileña Adriana Verejão, cuya obra es interpretada por Alice Heeren quien evidencia los entrecruzamientos de raza/género y la fragmentación social. Ese tipo de interpretación es posible apreciarla también en el texto de Jamie Ratliff sobre la obra fotográfica de Daniela Rosell en su serie "Ricas y famosas", donde se cuestiona el tema del espacio doméstico, abordado en otros artículos anteriormente mencionados. Ratliff parte de una lectura del espacio del "hogar" como piedra de toque de la nación mexicana, un espacio que tradicionalmente definió lo que significaba ser mujer. En el texto, el hogar aparece como un espacio de representación en el cual el poder y la autoridad del Estado invaden las vidas de los ciudadanos y permiten la reproducción del poder, por medio de la perpetuación de los roles de género tradicionales.

14 Finalmente, nos gustaría comentar que este número de la revista incluye también una sección de "Reprise" en la que tratamos de ofrecer al lector textos clásicos sobre el arte y el género en América Latina, que se encuentran poco accesibles al público general. El texto de Laura Malosetti Costa, "El rapto de las cautivas blancas: un aspecto erótico de la barbarie en la plástica Rioplatense del siglo XIX", es uno de los ejemplos pioneros en la interpretación, por medio de una perspectiva de género, del mito blanco de la conquista en la literatura y en la plástica. Con mucha creatividad y originalidad, Malosetti entrecruza en este artículo ya clásico en el corpus de sus textos, las fuentes literarias y visuales sobre el rapto de mujeres blancas por los indios (y aborda tanto escenas de rapto como de cautiverio) con lo que señala el cruce entre los problemas de género, raza y clase social, de manera pionera. Por otro lado, el artículo de Angélica Velázquez, "Juliana and Josefa Sanromán: The Representation of Bourgeois Domesticity 
in Mexico, 1850-1860" nos presenta la producción plástica de las hermanas Sanromán, ambas alumnas del director del ramo de pintura en la Academia de San Carlos, mostrando así la forma en la que las señoritas decimonónicas mexicanas podían acceder a una formación pictórica, la temática que favorecían en sus obras, acorde a la clase social a la que pertenecían. Al lado de estos artículos, presentamos una entrevista con la Historiadora del Arte Argentina Laura Malosetti Costa, cuyas reflexiones sobre las relaciones entre arte, género y poder, presentes en sus constantes publicaciones, conferencias, ponencias etc...pueden ser tomadas como un estímulo para la reflexión y la investigación en otros contextos socio-políticos.

Los textos aquí reunidos, tomados desde los espacios geopolíticos de su producción, nos permiten calibrar los alcances de las reacciones frente a las construcciones canónicas de los géneros, "las guerras" contra tales cánones, como menciona Gloria Cortes, toda vez que hoy día resulta ya imposible evitar la productividad crítica y retórica de los contra-discursos (y las contra-historias) que los estereotipos de género, raza y clase generan en los países de América Latina

\section{BIBLIOGRAFÍA}

ARRUDA, Lina Alves (2013). Estratégias desconstrutivas: a crítica feminista da representação". Dissertação de Mestrado em Artes Visuais, Escola de Comunicações e Artes, São Paulo, 2013. BROUDE, Norma Broudeand and GARRARD, Marry (1982). Feminist Art History: Questioning the Litany.New York, Harper \& Row Publishers.

BARTRA, Eli. (2005) Mujeres en el Arte Popular. De Promesas, traiciones, monstrous y celebridades. México, Universidad Autónoma Metropolitana.

CANCLINI, Nestor G. (1990). Culturashibridas. Estrategias para entrar y salir de lamodernidad, México, Grijalbo.

DE DIEGO, Estrella (2008). "Durante El feminismo de la igualdad: Historiografía, teoría y prácticas artísticas”. Madrid, Exitbook: feminismo y arte de género, n.9.

DE LAURETIS, Teresa. (1987). Technologies of Gender.Essays on Theory, Film and Fiction.Bloominton, Indiana University Press.

DOROTINSKY, Deborah (2008). “Mirar desde los márgenes o los márgenes de la mirada. Fotografía por dos mujeres indígenas de Chiapas”, Debate Feminista, Año 19,Vol. 38, octubre 2008.

EDER, Rita. (1982). “Las mujeres artistas en México”, en Anales del Instituto de Investigaciones Estéticas, México, IIE-UNAM, Vol XIII, núm. 50, tomo 2, pp.251-259.

FERRAZ, Isa Grinspum (org.)(1994). Tempos de grossura. O design no impasse. Série Pontos sobre o Brasil. São Paulo, Instituto Lina Bo e P.M. Bardi.

GIASSON, Patrice (ed.) (2010). Brincando fronteras. Creaciones locales mexicanas y globalización. México, CONACULTA. 
GIUNTA, Andrea (2011). “Estrategias de lamodernidad en América Latina”. In: Escribir las Imágenes.Buenos Aires, SigloVeintiuno.

HOLANDA, Heloisa e HERKENHOFF, Paulo (2006).Manobras radicais. Rio de Janeiro, Centro Cultural Banco do Brasil.

HUYSSEN, Andrea (2010). “Geografias Del Modernismo”, In: Modernismo Después de la Posmodernidad.Buenos Aires, Gedisa Editorial.

JONES, Amelia (2011). “Les politique ssexuelles de The Dinner Party. Un contexte très critique (1996-2005), IN: DUMONT, Fabienne (ed). La Rébellion du Deuxième Sexe. L'histoire de l'art au crible des théories féministes anglo-américaines (1970-2000). Les Presses du Reél.

MAYAYO, Patricia. (2008). '¿Por qué no ha habido (grandes) artistas feministas en España?. Apuntes sobre una historia en busca de autor' en Xabier Arakistain; Lourdes Méndez:Producción artística y teoríadel arte: nuevos debates I, Vitoria, Centro Cultural MontehermosoKulturunea.

NOCHLIN, Linda (1991).Why there be no great women artists?”. In:_Art and Sexual Politics. New York, Macmillan Publishing Co.

POLLOCK, Griselda.(1999) “Tracing figures of presence, naming ciphers of abscence. Feminism, Imperialism, and Post modernity in the Work of SutapaBiswas". In BLOOM, Lisa. (1999) With other eyes. Looking at Race and Gender in Visual Culture.Minneapolis / Londres, University of Minnesota Press.

POLLOCK, Griselda (1977). “What's wrong with Images of Women?”, Screen Education, 1977, no24, 25-33.

RUBINO, Silvana (2009). Lina por escrito: textos escolhidos de Lina Bo Bardi, 1943-1991. São Paulo, Cosac\&Naify.

SANDOVAL, Chéla Sandova (1995).l "Feminist forms of Agency and Oppositional Consciousness: U.S. Third World Femenist Criticism" en KEGAN GARDINER, Judith. (1995) Provoking Agents.Genderand Agency in Theoryand Practice. Urbana and Chicago, Universityof Illinois Press. SARLO, Beatriz (1999). Una Modernidad Periférica: Buenos Aires 1920-1930. Buenos Aires, Nueva Vision. SCHWARTZ, Jorge (2003). Brasil: 1920-1950. Da Antropofagia à Brasília.São Paulo: Museu de Arte Brasileira/ Cosac \&Naify.

SIMIONI, Ana Paula C. (2008). Profissão artista: pintoras e escultoras acadêmicas brasileiras (1884-1922). São Paulo, EDUSP/FAPESP.

SPIVAK, Gayatri Chakravorty. (1986) “Imperialismand Sexual Difference”.oxford Literary Review 8, pp.517-529.

SOMMER, Doris. (2010). “Um romance irresistible: las ficciones fundacionales de América Latina”. In: BHABHA, Homi (compilador). Nación y Narración. Buenos Aires, SigloVeintiuno Editores.

\section{NOTAS}

1. Sobre la obra ver el vínculo: https://www.brooklynmuseum.org/exhibitions/dinner_party/

2. Es interesante notar que algunas autoras españolas establecieron críticas muy semejantes en tanto presentadas con la necesidad de repensar la hegemonía de los modelos anglosajones para explicar la producción artística en su país. Véase al respecto DE DIEGO (2008); MAYAYO (2008). Para profundizar en estos temas leer los artículos de Luana Saturnino y María Laura Rosa presentes en este número. 
3. La bibliografía sobre esa cuestión es extremadamente amplia para ser enlistada por completo. Destacamos: Canclini (1990), Sarlo (1999), Schwartz (2003); Huyssen (2010), Giunta (2011), entre otros.

4. Rubino, Silvana (2009).

5. Al respecto recomendamos el texto "Tempo de Grossura", inicialmente publicado em 1980, y organizado por Isa Grispum Ferraz (1994).

6. Las editoras están conscientes que el tema de las artistas de origen indígena no fue contemplado como sería debido. Al respecto recomendamos consultar, entre otros, Bartra (2005), Dorotinsky (2008) y Patrice Giasson, Editor (2010).

7. HOLANDA, H. e HERKENHOFF (2006).

\section{AUTORES}

\section{ANA PAULA CAVALCANTI SIMIONI}

IEB/USP

DEBORAH DOROTINSKY

UNAM

MAIRA DE LUCA

CRAL-EHESS 